\title{
Koro-Like Symptoms Associated with Schizophrenia
}

\author{
Selim El-Badri, Adrian Leathart \\ Adult Mental Health Services, Waikato District Health Board, Hamilton, New Zealand \\ Email: Selim.El-Badri@waikatodhb.health.nz
}

How to cite this paper: El-Badri, S. and Leathart, A. (2017) Koro-Like Symptoms Associated with Schizophrenia. Open Journal of Psychiatry, 7, 213-219.

https://doi.org/10.4236/ojpsych.2017.73019

Received: April 8, 2017

Accepted: July 25, 2017

Published: July 28, 2017

Copyright $\odot 2017$ by authors and Scientific Research Publishing Inc. This work is licensed under the Creative Commons Attribution International License (CC BY 4.0).

http://creativecommons.org/licenses/by/4.0/

\begin{abstract}
Koro syndrome is a culture-related psychiatric disorder which is endemic in South-East Asia and is characterised by the sudden development of fear that one's penis is shrinking into the abdomen and may result in death. A number of cases with Koro-like symptoms have been reported among Caucasians in association with a variety of neuropsychiatric pathology. This case report describes a case of Koro-like symptoms associated with schizophrenia in a 66 years old male European living in a Western Country.
\end{abstract}

\section{Keywords}

Koro, Koro-Like Syndrome, Genital Retraction Syndrome, Culture-Bound Syndrome

\section{Introduction}

Koro is a culture-bound syndrome which occurs predominantly in South-East Asia sometimes in epidemic forms [1] [2]. It is characterised, in its typical form, by acute anxiety, with complaints in men of a shrinking penis or fear of penile retraction into the abdomen and subsequent death. Patients often try to prevent this by pulling their genitals manually or with the aid of some instrument. Sometimes other men are recruited to help out with this. Several sporadic cases of Koro-like states have been reported among Caucasians mostly associated with psychiatric or physical disorders [3] [4] [5]. The classification of culture-bound syndromes such as Koro within the major diagnostic systems is usually dependent on their predominant symptoms. However, clarifying the predominant symptoms of Koro, has proved to be a challenging exercise [6]. It is also difficult to differentiate qualitatively the culture-bound syndrome from apparently similar, isolated western cases. Therefore, Koro provides an example of shifting diagnostic classifications because of changing decisions about which symptoms are 
predominant. Koro may be viewed as a cultural expression of a number of states including anxiety neurosis, conversion disorder, depersonalization disorder, atypical psychotic disorder, and body image disorder [4]. The pathogenesis of Koro is poorly understood. The endemic and epidemic forms of Koro are more likely to be typically culture-bound syndromes where traditional beliefs seem to play a significant role in its occurrence [2] [7]. In this context, Koro is related to the inherent interaction between social and cultural factors and the premorbid personality. However, sporadic cases of Koro-like symptoms in Caucasians have been reported in association with neuropsychiatric disorders and are related to the underlying co-morbidities. Some authors have attempted to distinguish between complete (classic, cultural, typical or primary) and incomplete (non-cultural, atypical or secondary) forms of Koro [8] [9]. Cultural or primary forms are regarded as complete forms as they have all the symptoms required for diagnosis without significant co-morbidity and are said to involve a cultural belief which plays a role in the initiation and spread of the condition in the community [2] [7] [8] [9]. Incomplete or Koro-like states are believed to represent co-morbidities with other neuropsychiatric or neurological conditions. Koro is an example of the tension between the universality of general psychiatric symptoms as seen in western conceptions of mental illness, and the realization that people in nonwestern cultures experience psychiatric trauma and anxieties differently [10]. However it is clear that Koro can be found in all cultures. Even in non-western cases, there is a great heterogeneity among cases, depending on the local criteria used to diagnose Koro [10]. This case report describes a case of Koro-like symptoms associated with paranoid schizophrenia in a 66 years old New Zealand European male.

\section{Case Presentation}

The patient is a 66-year old New Zealand European man with a longstanding psychiatric history of paranoid schizophrenia dating back to 2000. The central symptoms of his psychotic presentation included auditory hallucinations calling him a paedophile and homosexual, and delusions of persecution by witchcraft involving his neighbours. Over the past few years he has believed that his penis is shrinking. He was not sure if his penis would disappear completely or retract into his abdomen, but if it did, he did not think that this would result in death. He believed that there was nothing that would stop the penile shrinkage. He reported that he had gone from standing up to sitting down while urinating because he considered his penis was too short to hold onto. He said he was constantly worried and concerned about this but he did not report any symptoms of severe anxiety or panic attacks. At times he became preoccupied with the frequency of his toileting and started using a strict time table that he followed consistently. He did not give a specific reason for doing that other than avoiding "having an accident". His thought processes were irrational at times and his insight was limited. He was quite convinced about being the subject of witchcraft. Interestingly, he did not attribute the shrinking of his penis to witchcraft, but 
said that the shrinking of his penis was caused by nerve damage that he sustained during a motor vehicle accident (MVA) in 1972. He reportedly suffered a concussion in the MVA but there was nothing to suggest that he had sustained any peripheral nerve damage. There was no history suggestive of seizures, organic illness or substance abuse. Physical examination, including genital examination did not reveal any abnormalities. Routine blood and urologic investigations were normal. During the initial stages of his illness he was prescribed Risperidone up to $6 \mathrm{mg}$ daily which was changed to Olanzapine $20 \mathrm{mg}$ daily due to poor response. His core psychotic symptoms have resolved. However, he has continued to complain of penile shrinkage which is of a delusional quality and variable intensity. He has had intermittent and short-lived depressive symptoms with self-neglect and diminished interest which responded favourably to the addition of paroxetine $40 \mathrm{mg}$ daily. His delusional belief concerning penile retraction has varied in intensity over time but has never resolved completely.

Since the onset of mental illness in 2000, he has had persistent deficits in life skills. He frequently got into conflicts with his neighbours and moved out. He was homeless for at least a year and a half before he was transferred to supported accommodation in 2014. His parents are deceased and he is the oldest of three siblings. He is alienated from his family and has no contact with his siblings. There is no known family history of mental illness. He did not report any significant adverse birth or childhood life events. He said he was committed to playing football as a teenager and did not get involved with women. He enjoyed playing football and represented his region and was the captain of the under-16 team. He left school at 17 and passed a one year university entrance examination in accountancy and English. He did not report having any premarital sexual relationships. He married twice but did not father any children. He got married in 1982 and divorced after 4 years due to arguments, and married again for only one month when his wife left him and has been single ever since. He denied having any sexual difficulties. Further psychosexual screening revealed no significant areas of concerns. He worked as an accounting clerk, then as a locomotive assistant for the Railways, then as a grounds man for Parks and Reserves for a few years. He has been on a benefit since 1995 .

\section{Discussion}

Koro was once believed to be unique to a specific culture (Southern China), hence the use of the term culture-bound syndrome. However, it has since been reported among diverse ethnic and religious groups in Asia, Africa and the western world leading to speculations that Koro may not be a truly culturebound syndrome [4] [11] [12] [13]. The variability in Koro symptom presentations and its universality seem to suggest that Koro is neither culture bound nor a true syndrome. The notion of vanishing penis and magically induced impotence is known in folk belief from ancient times to the present and has been described in many parts of the world including Europe [14] [15]. Furthermore, Koro treatment methods are also variable ranging from a variety of folk reme- 
dies commonly employed in south-east Asia and Africa to psychopharmacology or psychotherapy typically used for cases occurring in the western world. Difference in treatment methods is regarded by some authors as a cultural recognition of Koro as a real syndrome existing in different cultures [10].

Koro epidemics appear to reflect the role of traditional beliefs and other related psychosocial triggers in the genesis and spread of the typical syndrome. In this context, it is considered to be a psychogenic reactive state closely related to the socio-cultural construct of sexual somatization. However, sporadic cases of Koro-like phenomena in the Western world and in non-Asian patients seem to indicate an atypical variety with predisposing factors that appear to be independent of culture. Therefore, Koro in Asian epidemics represents the complete form with all of the core features including fear of penile shrinkage, disappearance into the abdomen and consequent death in the absence of any significant co-morbidity. By contrast, atypical, secondary or Koro-like states are associated with a primary psychiatric or neurological disorder, or possible drug use [9]. In some of these cases the belief was of a delusional nature that was part of another symptom constellation. The patient in this report suffered from longstanding paranoid schizophrenia and believed that his penis was shrinking despite the lack of any objective evidence of this and could not be reassured otherwise. At the same time he did not display any of the other features of the classic Koro syndrome such as the fear of disappearance of the organ into the abdomen and consequent death. This is consistent with other reported non-Asian cases of Koro-like states which occurred in the context of psychiatric or physical pathology [3] [4] [5]. In the case reported here the use of antipsychotic medication led to the control of the auditory hallucinations and persecutory delusions. A common finding in some Koro-affected individuals is conflicting feelings about sexuality and sexual identity. This was absent in this case. It is also unclear if the sexual theme of his auditory hallucinations (e.g., calling him a paedophile and homosexual) was related to the development of his belief concerning penile shrinkage. It is also unclear if there was any relationship between his delusions of being the subject of witchcraft and the development of his belief of penile shrinkage. He did not think that the penile retraction was caused or triggered by pernicious or mysterious influences or magic. He believed that the shrinking of his penis must have been related to the MVA that he had had many years previously. Despite treatment, his belief persisted however he spontaneously stopped complaining about it. The underlying dynamics or mechanisms resulting in chronicity of symptoms of Koro are not clear. The patient continued to display some negative symptoms of schizophrenia such as blunted affect and lack of motivation. We argue that Koro-like states or symptoms may possibly exist more frequently than reported in schizophrenia, because patients may be reluctant to report their symptoms due to shame and guilt.

The question of whether Koro is a unique cultural syndrome or merely the cultural expression of a universal phenomenon has been raised by a number of authors in the past. Sporadic Koro has been described in association with brain 
tumour, temporal lobe epilepsy, stroke, drug abuse, depressive illness, phobic disorder and schizophrenia [5]. While a typical Koro epidemic is usually accompanied by acute anxiety and panic, in Koro-like cases the clinical presentation seems to be related to the underlying disorder [16]. Koro-like symptoms may present as a delusion lasting for years in the context of schizophrenia [5]. Similarly, in the present case the patient displayed a belief that his penis was shrinking in the absence of any acute anxiety or panic symptoms and the development of his belief was not closely related to his intermittent depressive symptomatology. Our patient's fixed belief could be explained as being a symptom of the underlying schizophrenia as disturbances of body perception are not uncommon features of this disorder [17]. The association of Koro symptoms with schizophrenia has been reported by numerous authors [1] [5] [18]-[25]. Ungvari and Mullen reported a case of penile delusional retraction associated with schizophrenia in a middle aged European male from New Zealand similar to the present case. In our case the absence of the belief that the penis will disappear into the abdomen or cause death is consistent with other reported western cases. However, in the present case there were no associated concerns often reported in western cases such as becoming impotent and losing virility which in turn may symbolize a concern about loss of status and loss of sexual control. Clinicians should enquire about such symptoms more routinely, as the nature of the symptoms may make patients reluctant to spontaneously report them.

\section{Conclusion}

It is clear that Koro can be found in all cultures and there is a great heterogeneity even among non-western cases. However, socio cultural context and associated comorbidities are likely to influence the development of classic Koro or Koro-like conditions and therefore must be taken into account when making a diagnostic formulation. More research is needed to ascertain how best to classify Koro syndrome and integrate cultural influences into diagnostic practices.

\section{Consent}

The patient described in this case report has given written informed consent to the publishing of his clinical history.

\section{References}

[1] Yap, P.M. (1965) Koro-A Culture-Bound Depersonalization Syndrome. British Journal of Psychiatry, 111, 43-50. https://doi.org/10.1192/bjp.111.470.43

[2] Tseng, W.S., Mo, K.-M., Hsu, J., Li, L.-S., Ou, L.-W., Chen G.-Q. and Jiang, D.-W. (1988) A Sociocultural Study of Koro Epidemics in Guangdong, China. American Journal of Psychiatry, 145, 1538-1543. https://doi.org/10.1176/ajp.145.12.1538

[3] Berrios, G.E. and Morley, S.A. (1984) Koro-Like Symptoms in a Non-Chinese Subject. British Journal of Psychiatry, 145, 331-334. https://doi.org/10.1192/bjp.145.3.331

[4] Bernstein, R.L. and Gaw, A.C. (1990) Koro: Proposed Classification for DSM-IV. 
American Journal of Psychiatry, 147, 1670-1674.

https://doi.org/10.1176/ajp.147.12.1670

[5] Ungvari, G.S. and Mullen, R.S. (1994) Koro: the Delusion of Penile Retraction. Urology, 43, 883-885. https://doi.org/10.1016/0090-4295(94)90160-0

[6] Guarnaccia, P.J. and Rogler, L.H. (1999) Research on Culture-Bound Syndromes: New Directions. American Journal of Psychiatry, 156, 1322-1327.

[7] Mun, C. (1968) Epidemic Koro in Singapore. British Medical Journal, 1, 640-641. https://doi.org/10.1136/bmj.1.5592.640-b

[8] Adeniran, R.A. and Jones, J.R. (1994) Koro: Culture-Bound Disorder or Universal Symptom? British Journal of Psychiatry, 164, 559-561. https://doi.org/10.1192/bjp.164.4.559

[9] Chowdhury, A.N. (1996) The Definition and Classification of Koro. Culture, Medicine and Psychiatry, 20, 41-65. https://doi.org/10.1007/BF00118750

[10] Crozier, I. (2011) Making up Koro: Multiplicity, Psychiatry, Culture, and Penis-Shrinking Anxieties. Journal of the History of Medicine and Allied Sciences, 67, 36-70. https://doi.org/10.1093/jhmas/jrr008

[11] Dzokoto, V.A. and Adams, G. (2005) Understanding Genital-Shrinking Epidemics in West Africa: Koro, Juju or Mass Psychogenic Illness? Culture, Medicine and Psychiatry, 29, 53-78. https://doi.org/10.1007/s11013-005-4623-8

[12] Mather, C. (2005) Accusations of Genital Theft: A Case from Northern Ghana. Culture, Medicine and Psychiatry, 29, 33-52.

[13] Kumar, R., Phookun, H.R. and Datta, A. (2014) Epidemic of Koro in North East India: An Observational Cross-Sectional Study. Asian Journal of Psychiatry, 12, 113 117. https://doi.org/10.1016/j.ajp.2014.07.006

[14] Smith, M. (2002) The Flying Phallus and the Laughing Inquisitor: Penis Theft in the "Malleus Maleficarum". Journal of Folklore Research, 39, 85-117.

[15] Mattelaer, J.J. and Jilek, W. (2007) Koro-The Psychological Disappearance of the Penis. Journal of Sexual Medicine, 4, 1509-1515. https://doi.org/10.1111/j.1743-6109.2007.00586.x

[16] Garlipp, P. (2008) Koro-A Culture-Bound Phenomenon: Intercultural Psychiatric Implications. German Journal of Psychiatry, 11, 21-28.

[17] Priebe, S. and Röhricht, F. (2001) Specific Body Image Pathology in Acute Schizophrenia. Psychiatry Research, 101, 289-301. https://doi.org/10.1016/S0165-1781(01)00214-1

[18] Edwards, J.G. (1970) The Koro Pattern of Depersonalization in an American Schizophrenic Patient. American Journal of Psychiatry, 126, 1171-1173. https://doi.org/10.1176/ajp.126.8.1171

[19] Cremona, A. (1981) Another Case of Koro in a Briton. British Journal of Psychiatry, 138, 180-181. https://doi.org/10.1192/bjp.138.2.180

[20] Ang, P.C. and Weller, M.P. (1984) Koro and Psychosis. British Journal of Psychiatry, 145, 335. https://doi.org/10.1192/bjp.145.3.335

[21] Devan, G.S. and Hong, O.S. (1987) Koro and Schizophrenia in Singapore. British Journal of Psychiatry, 150, 106-107. https://doi.org/10.1192/bjp.150.1.106

[22] Kendall, E.M. and Jenkins, P.L. (1987) Koro in an American Man. American Journal of Psychiatry, 144, 1621. https://doi.org/10.1176/ajp.144.12.1621a

[23] Kranzler, H.R. and Shah, P.J. (1988) Atypical Koro. British Journal of Psychiatry, 152, 579-580. https://doi.org/10.1192/bjp.152.4.579b

[24] Afonso, P., Saraiva, S. and Gameiro, Z. (2013) Schizophrenia Presenting with 
Koro-Like Symptoms. The Journal of Neuropsychiatry \& Clinical Neurosciences, 25, E32. https://doi.org/10.1176/appi.neuropsych.12020037

[25] Stip, E., Bergeron, T., Lavigueur, C., Fabian, J.L. and Ait Bentalebet, L. (2007) Le syndrome de Koro. Annales Medico-Psychologiques, 165, 147-153.

https://doi.org/10.1016/j.amp.2005.04.015

Submit or recommend next manuscript to SCIRP and we will provide best service for you:

Accepting pre-submission inquiries through Email, Facebook, LinkedIn, Twitter, etc. A wide selection of journals (inclusive of 9 subjects, more than 200 journals)

Providing 24-hour high-quality service

User-friendly online submission system

Fair and swift peer-review system

Efficient typesetting and proofreading procedure

Display of the result of downloads and visits, as well as the number of cited articles Maximum dissemination of your research work

Submit your manuscript at: http://papersubmission.scirp.org/

Or contact ojpsych@scirp.org 